\title{
Expression of B-cell transcription factors in primary cutaneous B-cell lymphoma
}

\author{
Juliette J Hoefnagel ${ }^{1}$, Marÿn MS Mulder ${ }^{2}$, Enno Dreef ${ }^{3}$, Patty M Jansen ${ }^{3}$, Steven T Pals ${ }^{2}$, \\ Chris JLM Meijer ${ }^{4}$, Rein Willemze ${ }^{1}$ and Maarten H Vermeer ${ }^{1}$
}

\begin{abstract}
${ }^{1}$ Department of Dermatology, Leiden University Medical Center, Leiden, The Netherlands; ${ }^{2}$ Department of Pathology, Academic Medical Center, University of Amsterdam, Amsterdam, The Netherlands; ${ }^{3}$ Department of Pathology, Leiden University Medical Center, Leiden, The Netherlands and ${ }^{4}$ Department of Pathology, Vrije Universiteit Medical Center, Amsterdam, The Netherlands
\end{abstract}

\begin{abstract}
Expression patterns of eight transcription factors involved in different stages of B-cell development were investigated in a large group of primary cutaneous B-cell lymphomas and compared with expression patterns during normal B-cell development. The following transcription factors were investigated: Pax-5, PU.1, Oct2, BOB.1, Bcl-6, Mum1/IRF4, Blimp-1 and FOXP1. Primary cutaneous large B-cell lymphomas, leg type showed aberrant coexpression of Bcl-6 and Mum1/IRF4 and in addition strong expression of FOXP1. Expression of FOXP1 and Mum1/IRF4 strongly suggests an activated B-cell type of origin. In contrast, primary cutaneous follicle center lymphomas showed expression of Bcl-6, Pax-5, PU.1, Oct2 and BOB.1, but not of Mum1/IRF4, Blimp-1 and FOXP1. Primary cutaneous marginal zone B-cell lymphoma showed expression of Pax-5, PU.1, Oct2 and BOB.1, but not Bcl-6 by the neoplastic B-cells, and Mum1/IRF4 and Blimp-1 by the neoplastic plasma cells. In conclusion, in primary cutaneous follicle center lymphoma and primary cutaneous marginal zone B-cell lymphoma expression patterns were observed similar to their supposed benign counterparts, germinal center B-cells and postgerminal center B-cells, respectively, which might reflect their indolent clinical behaviour and excellent prognosis. In contrast, the activated B-cell expression pattern in the group of primary cutaneous large B-cell lymphoma, leg type may contribute to its poor prognosis and Mum1/IRF4 and FOXP1 may serve as additional diagnostic markers for this type of primary cutaneous B-cell lymphoma.
\end{abstract}

Modern Pathology (2006) 19, 1270-1276. doi:10.1038/modpathol.3800650; published online 16 June 2006

Keywords: B-cell transcription factors; primary cutaneous B-cell lymphoma

The process of B-cell development, in which early B-cell precursors mature into terminally differentiated plasma cells, is strictly regulated by a large number of B-cell transcription factors. Distinct stages of B-cell development are characterized by a particular expression pattern of these factors. ${ }^{1-3}$ With respect to B-cell lymphomas, expression patterns of transcription factors are of particular importance for several reasons: Firstly, they may provide information about the maturation stage of the cell of origin. Secondly, genetic defects including chromosomal translocations and mutations can result in deregulation of the transcriptional machinery in B-cells and are considered to be of major importance in the pathogenesis of B-cell

Correspondence: Dr JJ Hoefnagel, MD, Department of Dermatology, B1-Q, Leiden University Medical Center, PO Box 9600, 2300 RC Leiden, The Netherlands.

E-mail: j.j.hoefnagel@lumc.nl

Received 20 March 2006; revised 17 May 2006; accepted 22 May 2006; published online 16 June 2006 lymphomas. ${ }^{4}$ Finally, in some B-cell lymphoma subtypes, expression of a specific transcription factor can be used as a diagnostic or prognostic marker. ${ }^{5}$

Recent studies have also established the significance of B-cell transcription factors in the diagnosis and pathogenesis of primary cutaneous B-cell lymphomas. ${ }^{6-8}$ These lymphomas represent a heterogeneous group of B-cell non-Hodgkin's lymphomas presenting in the skin with no evidence of extracutaneous disease at the time of diagnosis. According to the new World Health Organization-European Organization for Research and Treatment of Cancer (WHO-EORTC) classification three clinicopathologically well-defined groups of primary cutaneous B-cell lymphomas can be distinguished: primary cutaneous follicle center lymphoma, primary cutaneous large B-cell lymphoma, leg type and primary cutaneous marginal zone B-cell lymphoma. ${ }^{9}$ Microarray analysis showed high expression values of transcription factors multiple myeloma-1/interferon regulatory factor $4(M U M 1 / I R F 4)$ and OCT2 in 
primary cutaneous large B-cell lymphoma, leg type, compared to primary cutaneous follicle center lymphoma. ${ }^{8}$ Consistently, these studies showed that primary cutaneous follicle center lymphoma and primary cutaneous large B-cell lymphoma, leg type have distinct gene expression profiles, similar to that of germinal center B-cel type (GCB-type) diffuse large B-cell lymphoma (DLBCL) and activated B-cell type (ABC-type) DLBCL, respectively.

These results prompted us to investigate the expression of a large panel of B-cell transcription factors expressed throughout the entire spectrum of B-cell maturation, in primary cutaneous B-cell lymphoma by immunohistochemistry. Three main groups of B-cell transcription factors were studied: (1) B-cell transcription factors expressed already in early B-cell development stages in bone marrow, including Pax-5 and PU.1; (2) B-cell transcription factors expressed in mature B-cells (mantle cells and (post) germinal center cells), including Oct2, its cofactor BOB.1 and the germinal center marker Bcl6; (3) B-cell transcription factors associated with plasmacellular differentiation, including Mum1/ IRF4 and Blimp-1. In addition, we studied expression of transcription factor FOXP1 because of its association with the ABC-type of nodal DLBCL. ${ }^{10,11}$

The aim of the present study is (1) to compare the expression patterns in primary cutaneous B-cell lymphoma with physiological patterns in normal B-cells in order to detect aberrant expression with potential pathogenetic significance and (2) to find out whether expression of some of these B-cell transcription factors can be used in the differential diagnosis of these lymphomas.

\section{Methods}

\section{Patients}

Pretreatment biopsies obtained at the time of diagnosis from 29 patients with a primary cutaneous B-cell lymphoma, including 11 primary cutaneous large B-cell lymphomas, leg type, nine primary cutaneous follicle center lymphomas and nine primary cutaneous marginal zone B-cell lymphomas, were investigated. Tonsils and skin biopsy specimens from five patients with a pseudo-B-cell lymphoma were included as controls. Patients with primary cutaneous B-cell lymphoma were defined according to the criteria of the WHO-EORTC classification. $^{9}$ All 11 primary cutaneous large Bcell lymphoma, leg type cases showed diffuse infiltrates predominantly consisting of large round cells strongly expressing Bcl-2.

The biopsies of the nine primary cutaneous follicle center lymphoma cases displayed diffuse dermal infiltrates mainly consisting of medium to large-sized cleaved cells (centrocytes), did not show a (partly) follicular growth pattern and were consistently Bcl-2 negative. In all cases of primary cutaneous marginal zone B-cell lymphoma the diagnosis was supported by the presence of monotypic immunoglobulin light chain expression by lymphoplasmacytoid cells and plasma cells on paraffin sections.

In all primary cutaneous B-cell lymphoma cases, there was no evidence of extracutaneous disease at the time of diagnosis as assessed by adequate staging procedures, which included physical examination, complete blood cell counts, computed tomography of chest and abdomen and bone marrow biopsy. After a median follow-up period of 62 months (range: 8-112 months), eight out of nine patients with a primary cutaneous follicle center lymphoma and eight out of nine patients with a primary cutaneous marginal zone B-cell lymphoma were alive without evidence of disease, one out of nine patients with a primary cutaneous follicle center lymphoma and one out of nine patients with a primary cutaneous marginal zone B-cell lymphoma died of another cause. Of the group of primary cutaneous large B-cell lymphoma, leg type, five out of 11 patients were alive without evidence of disease and six patients died as a result of lymphoma.

\section{Immunohistochemistry}

Immunohistochemical staining was performed on $3 \mu \mathrm{m}$ sections of formalin-fixed, paraffin-embedded tissues using standard procedures. After antigen retrieval by boiling for $10 \mathrm{~min}$ in $1.0 \mathrm{mM}$ EDTA $(\mathrm{pH}$ 8.0) for Bcl-6, Pax-5, PU.1, Mum1/IRF4 and FOXP1, and in $10 \mathrm{mM}$ citrate buffer (pH 6.0) for Oct2, BOB.1, Blimp-1, CD79a and CD3, tissue sections were incubated overnight with antibodies against Bcl-6 (clone PG-B6p; dilution 1:200), CD20 (1:100), CD79a (1:400), CD3 (1:100) (DAKO ${ }^{\mathbb{R}}$, Glostrup, Denmark), PU.1 (1:400), BOB.1 (1:1600) (Santa Cruz Biotechnology ${ }^{\circledR}$, CA, USA), Oct2 (clone Oct-207, 1:200) (Novocastra ${ }^{\circledR}$, Klinipath, Duiven, The Netherlands), Pax-5 (1:400) (BD Bioscience Pharmingen ${ }^{\circledR}$, San Diego, CA, USA), Blimp-1 (1:100) (Abgent $^{\circledR}$, San Diego, USA), CD138 (1:800; Serotec ${ }^{\mathbb{R}}$, Oxford, UK), Mum1/IRF4 (1:100) and against FOXP1 (JC12, 1:200 in $10 \%$ normal human serum (NHS)). The antibodies against Mum1/IRF4 and FOXP1 were kindly provided by professor G Cattoretti, Institute of Cancer Genetics, Columbia University, New York, USA and Dr AH Banham, Nuffield Department of Clinical Laboratory Sciences, John Radcliffe Hospital, Oxford, UK, respectively.

For Pax-5, Oct2 and Mum1/IRF4, sections were then incubated with biotin-labeled rabbit-antimouse antibodies (1:200) and for PU.1, BOB.1 and Blimp-1 with biotin-labeled swine-anti-rabbit antibody (1:400). Immunoreactivity was detected using a streptavidin-biotin-peroxidase complex (sABCHRP; 1:100; DAKO ${ }^{\mathbb{R}}$ ). For FOXP1, sections were incubated with Envision HRP-labeled detection system $\left(\mathrm{DAKO}^{\mathbb{R}}\right)$ and immunoreactivity was detected using diamino-benzidine (DAB)-reagents and counterstaining with hematoxylin. All second- 
ary and tertiary antibodies were incubated for $30 \mathrm{~min}$ in $1 \% \mathrm{PBS} / \mathrm{BSA}$ at room temperature.

The antibodies against B-cell- (CD20, CD79a), plasma cell- (CD138) and T-cell- (CD3, CD5) antigens were used to verify the localization of the neoplastic B-cells and reactive T-cells. Staining of transcription factors was scored into three groups as follows: 0$24 \%$ positive staining tumor cells, $25-49 \%$ positive staining tumor cells and $50 \%$ or more positive cells. Expression was considered as positive, if $25 \%$ or more of the neoplastic cells stained, and as negative if $<25 \%$ of the neoplastic cells stained.

\section{Results}

A summary of the results is provided in Table 1 . In Table 2 the expression of investigated B-cell transcription factors in normal B-cell development is displayed. ${ }^{12-23}$

\section{Early B-Cell Transcription Factors: Pax-5 and PU.1 Expression}

In pseudo B-cell lymphomas and tonsils, Pax-5 was strongly expressed by mantle cells and less intensely by follicle center cells, whereas plasma cells were always Pax-5 negative. In both groups of primary cutaneous follicle center lymphoma and primary cutaneous large B-cell lymphoma, leg type, all tumor cells were Pax-5 positive. In primary cutaneous marginal zone B-cell lymphoma, Pax-5 expression was observed in the small neoplastic B-cells, but the monotypic plasma cells were always negative.

Table 1 Summary of immunohistochemistry results in primary cutaneous B-cell lymphomas

\begin{tabular}{|c|c|c|c|c|c|c|c|c|c|c|c|c|}
\hline & \multicolumn{3}{|c|}{ Pax-5+ } & \multicolumn{3}{|c|}{ PU.1+ } & \multicolumn{3}{|c|}{ BOB.1+ } & \multicolumn{3}{|c|}{ Oct2+ } \\
\hline & $0-24 \%$ & $25-49 \%$ & $\geq 50 \%$ & $0-24 \%$ & $25-49 \%$ & $\geq 50 \%$ & $0-24 \%$ & $25-49 \%$ & $\geq 50 \%$ & $0-24 \%$ & $25-49 \%$ & $\geq 50 \%$ \\
\hline PLBCL, leg type & - & - & $11 / 11$ & - & $8 / 11$ & $3 / 11$ & - & - & $11 / 11$ & - & - & $11 / 11$ \\
\hline PCFCL & - & - & 9/9 & - & $6 / 9$ & $3 / 9$ & - & - & 9/9 & $2 / 9$ & - & 7/9 \\
\hline \multirow[t]{3}{*}{ PCMZL } & $2 / 9^{a}$ & - & $7 / 9$ & $2 / 9^{a}$ & - & $7 / 9$ & - & - & $9 / 9$ & $1 / 9$ & - & $8 / 9$ \\
\hline & \multicolumn{3}{|c|}{ Bcl-6+ } & \multicolumn{3}{|c|}{ Mum1/IRF4+ } & \multicolumn{3}{|c|}{ Blimp-1+ } & \multicolumn{3}{|c|}{ FOXP1+ } \\
\hline & $0-24 \%$ & $25-49 \%$ & $\geq 50 \%$ & $0-24 \%$ & $25-49 \%$ & $\geq 50 \%$ & $0-24 \%$ & $25-49 \%$ & $\geq 50 \%$ & $0-24 \%$ & $25-49 \%$ & $\geq 50 \%$ \\
\hline PLBCL, leg type & - & $1 / 11$ & $10 / 11$ & - & $2 / 11$ & $9 / 11$ & $11 / 11$ & - & - & $0 / 11$ & - & $11 / 11$ \\
\hline PCFCL & - & $1 / 9$ & 8/9 & $8 / 9$ & $1 / 9$ & - & 9/9 & - & - & $7 / 8$ & $1 / 8$ & - \\
\hline PCMZL & $9 / 9$ & - & - & $7 / 9$ & - & $2 / 9^{a}$ & $7 / 9$ & - & $2 / 9^{a}$ & $4 / 9$ & $3 / 9$ & $2 / 9$ \\
\hline
\end{tabular}

${ }^{\mathrm{a}}$ In two PCMZL cases more than 50\% plasma cells were present, which showed positive staining of both Mum1/IRF4 and Blimp-1, but were negative for PU.1 and Pax-5.

Abbreviations: PCLBCL, leg type: primary cutaneous large B-cell lymphoma, leg type; PCFCL: primary cutaneous follicle center lymphoma; PCMZL: primary cutaneous marginal zone B-cell lymphoma.

Table 2 Physiological expression of transcription factors in normal B-cells during B-cell development and comparison with different types of primary cutaneous B-cell lymphoma (CBCL)

\begin{tabular}{|c|c|c|c|c|c|c|c|c|}
\hline & \multicolumn{2}{|c|}{$\begin{array}{c}\text { Early } B \text {-cell } \\
\text { transcription factors }\end{array}$} & \multicolumn{3}{|c|}{$\begin{array}{c}\text { Mature B-cell } \\
\text { transcription factors }\end{array}$} & \multicolumn{2}{|c|}{$\begin{array}{c}\text { Plasmacellular } \\
\text { transcription factors }\end{array}$} & \multirow{2}{*}{$\begin{array}{c}\text { Activated B-cell type associated } \\
\text { transcription factor }\end{array}$} \\
\hline & $P a x-5$ & $P U .1$ & Oct2 & ВOB.1 & Bcl-6 & Mum1/IRF4 & Blimp-1 & \\
\hline \multicolumn{9}{|l|}{ Normal B-cells } \\
\hline Immature B-cell & + & + & - & - & - & - & - & ND \\
\hline Activated B-cell & + & ND & ND & ND & - & + & - & + \\
\hline Mantle B-cell & + & + & + & + & - & - & - & + \\
\hline $\begin{array}{l}\text { Germinal center } \\
\text { B-cell }\end{array}$ & + & + & + & + & + & - & - & $+1-$ \\
\hline Plasma cell & - & - & + & + & - & + & + & - \\
\hline \multicolumn{9}{|l|}{$C B C L$} \\
\hline PCLBCL, leg type & + & + & + & + & + & + & - & + \\
\hline PCFCL & + & + & + & + & + & - & - & - \\
\hline PCMZL & $t^{\mathrm{a}}$ & $t^{\mathrm{a}}$ & + & + & - & $-{ }^{\mathrm{a}}$ & $-{ }^{\mathrm{a}}$ & $+/-$ \\
\hline
\end{tabular}

${ }^{\mathrm{a}}$ The present monotypic plasma cells stained positive for Mum1/IRF4 and Blimp-1 and negative for Pax-5 and PU.1.

Abbreviations: ND, no data; PCLBCL, leg type, primary cutaneous large B-cell lymphoma, leg-type; PCFCL, primary cutaneous follicle center lymphoma; PCMZL, primary cutaneous marginal zone B-cell lymphoma. 
In pseudo B-cell lymphoma and tonsils, PU.1 expression was observed in the nuclei of all present B-cell populations, except in plasma cells that were consistently negative. PU.1 was expressed by the tumor cells of primary cutaneous large B-cell lymphoma, leg type and primary cutaneous follicle center lymphoma in all cases. In primary cutaneous marginal zone B-cell lymphoma, expression of PU.1 was observed in the small neoplastic B-cells, whereas plasma cells were PU.1 negative in all cases. Consistent with data from literature, PU.1 expression was observed in admixed histiocytes. ${ }^{16}$

\section{Mature B-Cell Transcription Factors: Oct2, BOB.1 and Bcl-6 Expression}

BOB.1 and Oct2 were detectable in all B-cell populations present in pseudo B-cell lymphomas and tonsils including mantle B-cells, germinal center B-cells and plasma cells. Expression of both Oct2 and BOB. 1 was observed in $90 \%$ or more of the tumor cells in all 11 cases of primary cutaneous large B-cell lymphoma, leg type. In seven of nine primary cutaneous follicle center lymphoma cases, expression of Oct2 was found in the majority of the tumor cells, whereas in two cases $<10 \%$ of the tumor cells stained positive. In this group, a weak to moderate staining intensity of Oct2 was observed. BOB.1 was expressed in $90 \%$ or more of the tumor cells in all primary cutaneous follicle center lymphoma cases. In eight of nine primary cutaneous marginal zone B-cell lymphoma cases, expression of Oct2 was observed in the neoplastic cells, whereas BOB.1 was expressed by the tumor cells in all nine cases.

In tonsils and pseudo B-cell lymphomas, Bcl-6 expression was restricted to the germinal center B-cells. The vast majority of the tumor cells of both primary cutaneous large B-cell lymphoma, leg type and primary cutaneous follicle center lymphoma stained positive for Bcl-6. Staining intensity could vary among individual tumor cells in both lymphomas. The tumor cells of primary cutaneous marginal zone B-cell lymphoma were Bcl-6 negative in all cases, but small clusters of Bcl-6 positive cells were observed in (remnants of) reactive germinal centers.

\section{Plasmacellular Transcription Factors: Mum1/IRF4 and Blimp-1 Expression}

In pseudo B-cell lymphomas and tonsils, Mum1/ IRF4 expression was found in the nuclei of plasma cells and a few germinal center cells. In eight of 11 primary cutaneous large B-cell lymphoma, leg type cases, strong staining of Mum1/IRF4 was observed in $80 \%$ or more of the tumor cells as illustrated in Figure 1a. In three cases percentages of positive staining tumor cells were between 30 and $60 \%$. In eight of nine primary cutaneous follicle center lymphoma, Mum1/IRF4 expression was found in at most $10 \%$ or less of the tumor cells, but in one case $30 \%$ of the tumor cells stained (Figure 1b). In primary cutaneous marginal zone B-cell lymphoma, Mum1/IRF4 expression was observed in plasma cells (more than $50 \%$ of the tumor in two cases), but small B-cells were Mum1/IRF4 negative in all cases (Figure 2a).

In tonsils and pseudo B-cell lymphomas, weak to moderate expression of Blimp-1 was observed in small clusters of plasma cells and in few scattered large germinal center cells. In cutaneous B-cell lymphoma, the tumor cells of all primary cutaneous large B-cell lymphoma, leg type and primary cutaneous follicle center lymphoma were Blimp-1 negative. In primary cutaneous marginal zone B-cell lymphoma, Blimp-1 expression was observed in plasma cells, but small B-cells stained negative in all cases (Figure 2b).
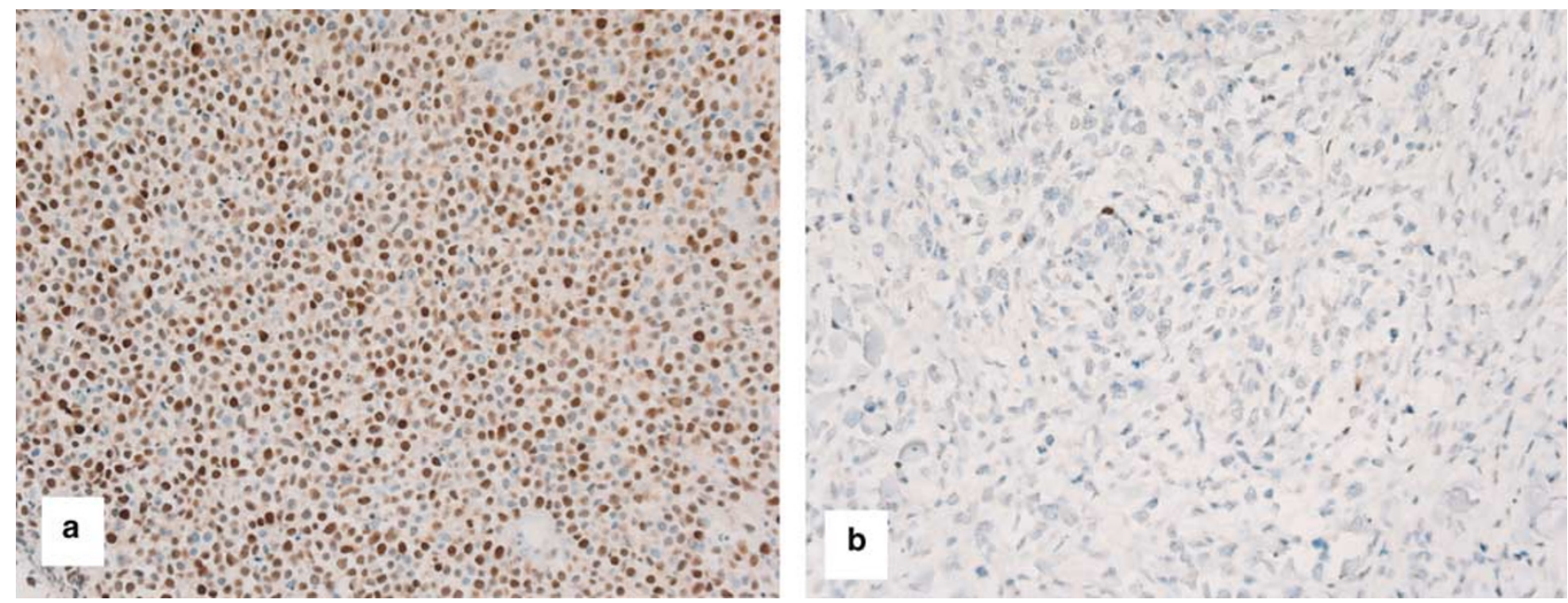

Figure 1 The tumor cells of primary cutaneous large B-cell lymphoma, leg type strongly express Mum1/IRF4 (a), whereas the tumor cells of primary cutaneous follicle center lymphoma are Mum1/IRF4 negative (b). 

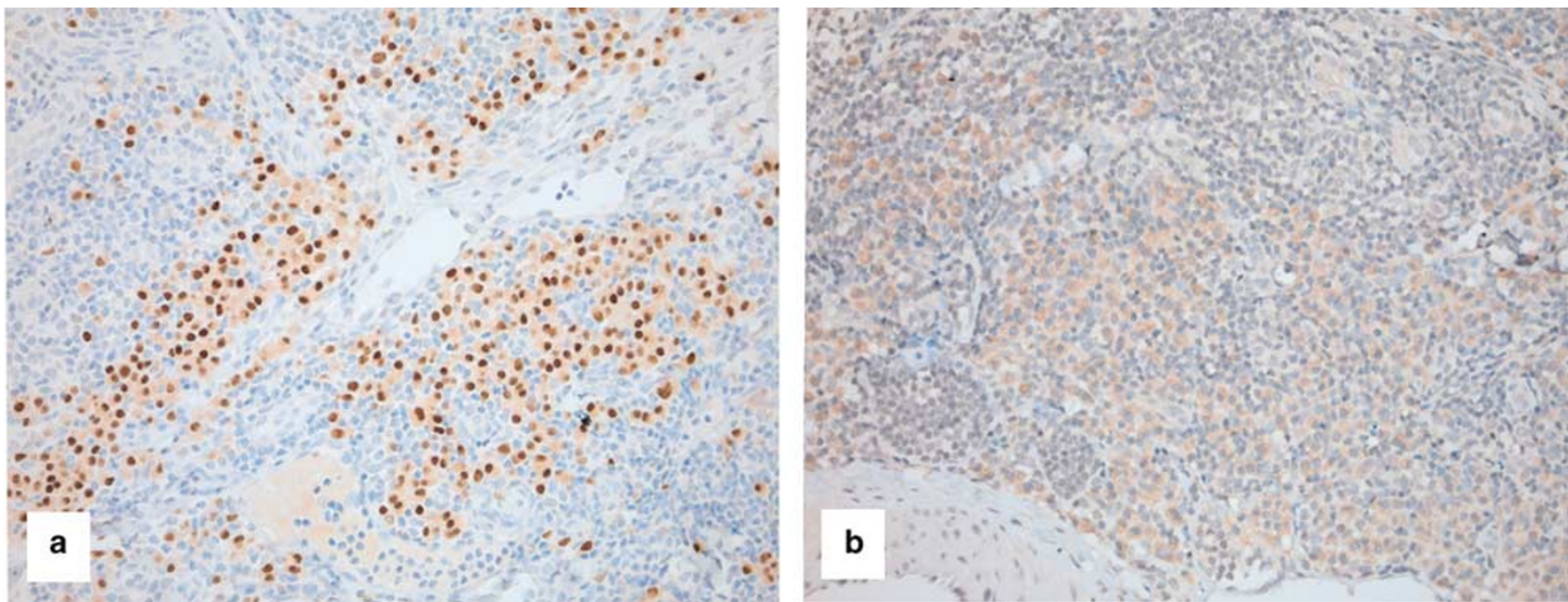

Figure 2 The monotypic plasma cells in primary cutaneous marginal zone B-cell lymphoma express Mum1/IRF4 (a) and Blimp-1 (b).
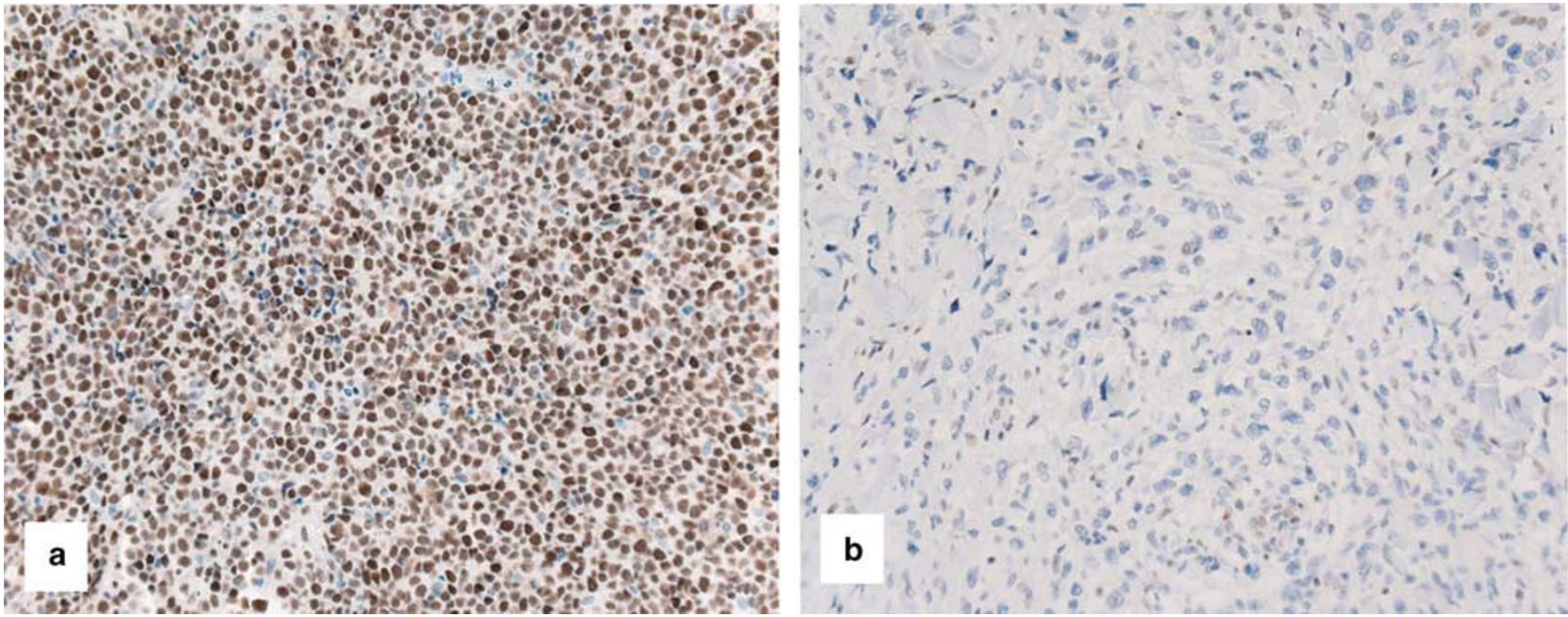

Figure 3 The tumor cells of primary cutaneous large B-cell lymphoma, leg type strongly express FOXP1 (a), whereas the tumor cells of primary cutaneous follicle center lymphoma are FOXP1 negative (b).

\section{FOXP1 Expression}

In pseudo B-cell lymphomas and tonsils, FOXP1 expression was predominantly found in the $\mathrm{B}$ and $\mathrm{T}$ cells in the mantle zone and in a variable proportion of germinal center B-cells, whereas plasma cells were negative.

All 11 cases of primary cutaneous large B-cell lymphoma, leg type displayed strong FOXP1 expression in $90 \%$ or more of the tumor cells (Figure 3a). In seven of eight investigated primary cutaneous follicle center lymphomas, tumor cells were FOXP1 negative or only a small minority (5-10\%) of the tumor cells showed FOXP1 expression (Figure $3 \mathrm{~b}$ ). In primary cutaneous marginal zone B-cell lymphoma, expression of FOXP1 was observed in more than $90 \%$ of the tumor cells in two cases, in three cases staining percentages between 25 and $49 \%$ of the tumor cells were found and in four cases $<25 \%$ of the tumor cells stained.

\section{Discussion}

In the present study, the expression of a broad panel of B-cell transcription factors reflecting the entire process of B-cell development was investigated in three different types of primary cutaneous B-cell lymphoma and compared with expression patterns in tonsils and cutaneous pseudo B-cell lymphomas. The main finding of the study was that primary cutaneous large B-cell lymphoma, leg type showed an aberrant expression pattern of B-cell transcription factors with coexpression of Bcl-6 and Mum1/ IRF4, markers which appear mutually exclusive during normal B-cell development. ${ }^{20,21}$ In addition, consistent expression of FOXP1 was found in this 
group. In contrast, primary cutaneous follicle center lymphoma and primary cutaneous marginal zone Bcell lymphoma showed expression patterns similar to those found in the benign counterparts of these lymphomas, germinal center cells and postgerminal center cells, respectively.

Coexpression of Bcl-6 and Mum1/IRF4 was found in all 11 primary cutaneous large B-cell lymphoma, leg type, and has also been reported in $50 \%$ of nodal DLBCL. ${ }^{20}$ Additonally, all primary cutaneous large B-cell lymphoma, leg type cases showed strong and uniform FOXP1 expression. In a recent study, Kodama et $a l^{24}$ found FOXP1 expression in $72 \%$ of the primary cutaneous B-cell lymphoma, leg type cases. FOXP1 is a member of the FOX-P subfamily of transcription factors with still ill-defined biological functions. ${ }^{23}$ Gene expression profiling studies showed that FOXP1 is expressed by activated peripheral blood B-cells and can be considered, like Mum1/ IRF4, as a marker of the ABC-type. ${ }^{5}$ Expression of Mum1/IRF4 and FOXP1 strongly suggests that the neoplastic B-cells in primary cutaneous large B-cell lymphoma, leg type have an activated B-cell origin, which is consistent with the results of our previous microarray study. ${ }^{8}$ However, the combined expression of activated B-cell markers, FOXP1 and Mum1/IRF4, and germinal center Bcl-6 in this group is a phenomenon that is difficult to interpret. The presence of chromosomal translocations involving BCL6 and immunoglobulin genes in $40 \%$ of primary cutaneous large B-cell lymphoma, leg type, including three of six investigated cases of the present study, suggests that at least a proportion of these lymphomas acquires aberrant Bcl-6 protein expression as a result of this chromosomal translocation. ${ }^{25}$

Furthermore, Banham et $a l^{10}$ showed an association between FOXP1 protein expression and a poor prognosis in nodal DLBCL. Interestingly, this FOXP1 expressing subset of DLBCL showed additional genotypic and phenotypic similarities to primary cutaneous large B-cell lymphoma, leg type including expression of Mum1/IRF4, expression of Bcl-2 in absence of chromosomal translocation $\mathrm{t}(14 ; 18)$ and an ABC gene expression profile. ${ }^{8,26,27}$ In another study, the chromosomal translocation $\mathrm{t}(3 ; 14)$ involving FOXP1 and IGH genes could be demonstrated in only one out of 10 FOXP1 expressing DLBCL cases as a underlying mechanism of FOXP1 protein expression. ${ }^{28}$ Using a fluorescent in situ hybridization (FISH)-analysis, we did not detect the chromosomal translocation $\mathrm{t}(3 ; 14)$ in any of the 11 PCLBCL, leg-type cases of the present study (data not shown).

The strong expression of Mum1/IRF4 and FOXP1 in all primary cutaneous large B-cell lymphoma, leg type, and the almost absent expression of these markers in the group of primary cutaneous follicle center lymphoma suggest that Mum1/IRF4 and FOXP1 may serve as useful diagnostic markers for primary cutaneous large B-cell lymphoma, leg type. Distinction between primary cutaneous follicle center lymphoma and primary cutaneous large Bcell lymphoma, leg type is considered important because of differences in prognosis (5-year survival $>95$ and $50 \%$, respectively) and the first choice of treatment (radiotherapy or systemic chemotherapy, respectively). ${ }^{9}$ However, the results of the present study and other studies suggest that expression of neither FOXP1 nor Mum1/IRF4 has prognostic significance in the group of primary cutaneous large B-cell lymphoma, leg type. ${ }^{24}$

In primary cutaneous follicle center lymphoma, an expression pattern similar to that of normal centrocytes and centroblasts was observed supporting their germinal center cell-origin. The tumor cells expressed early B-cell transcription factors Pax-5 and PU.1, germinal center marker Bcl-6, transcription factors Oct2 and BOB.1, but not the plasma cell and ABC markers Mum1/IRF4, Blimp-1 and FOXP1. In nodal follicular lymphoma a similar phenotype was demonstrated. ${ }^{15,17}$

In the group of primary cutaneous marginal zone B-cell lymphoma, the expression pattern of B-cell transcription factors observed in the tumor cells corresponded to a postgerminal center phenotype in all cases. The small neoplastic B-cells expressed early B-cell markers Pax-5 and PU.1, mature B-cell markers Oct2 and BOB.1, but were all negative for germinal center marker Bcl-6. As a result of immunohistochemical studies showing expression of Bcl-6 in primary cutaneous follicle center lymphoma, but not in primary cutaneous marginal zone B-cell lymphoma, Bcl-6 is currently used as an useful marker to differentiate between these two types of primary cutaneous B-cell lymphoma. ${ }^{6,7}$ The expression of FOXP1 was variable in primary cutaneous marginal zone B-cell lymphoma (see Table 1). Recent studies demonstrated that FOXP1 protein expression can be the result of the chromosomal translocation $\mathrm{t}(3 ; 14)$ as reported in $10 \%$ of a large group of extranodal MALT (mucosa-associated lymphoid tissue) lymphomas including two cases involving the skin. ${ }^{29}$ However, additional FISHanalysis on all nine cases from the present study did not reveal the presence of the $t(3 ; 14)$ translocation in this group (data not shown).

In conclusion, in primary cutaneous follicle center lymphoma and primary cutaneous marginal zone B-cell lymphoma expression patterns of B-cell transcription factors were observed similar to the supposed benign counterparts of these lymphomas, germinal center B-cells and postgerminal center Bcells, respectively. The presence of a physiological expression pattern of several important regulators of B-cell development might reflect the indolent clinical behaviour and excellent prognosis of both types of primary cutaneous B-cell lymphoma. In contrast, an ABC-type expression pattern was observed in primary cutaneous large B-cell lymphoma, leg type, which is likely to contribute to the 
pathogenesis and poor prognosis of this primary cutaneous B-cell lymphoma subtype.

\section{Acknowledgements}

JJH and MHV are supported by grants from Stichting De Drie Lichten and The Netherlands Organisation for Health Research and Development (907-00-066), respectively.

\section{References}

1 Bartholdy B, Matthias P. Transcriptional control of B-cell development and function. Gene 2004;327: $1-23$.

2 Matthias P, Rolink AG. Transcriptional networks in developing and mature B cells. Nat Rev Immunol 2005;5:497-508.

3 Shapiro-Shelef M, Calame K. Regulation of plasma-cell development. Nat Rev Immunol 2005;5:230-242.

4 Küppers R. Mechanisms of B-cell lymphoma pathogenesis. Nat Rev Cancer 2005;5:251-262.

5 Shaffer AL, Rosenwald A, Staudt LM. Lymphoid malignancies: the dark side of B-cell differentiation. Nat Rev Immunol 2002;2:920-932.

6 Hoefnagel JJ, Vermeer MH, Jansen PM, et al. Bcl-2, BCL-6 and CD10 expression in cutaneous B-cell lymphoma: further support for a follicle centre cell origin and differential diagnostic significance. Br J Dermatol 2003;149:1183-1191.

7 de Leval L, Harris NL, Longtine J, et al. Cutaneous B-cell lymphomas of follicular and marginal zone types. Use of BCL-6, CD10, Bcl-2, and CD21 in differential diagnosis and classification. Am J Surg Pathol 2001;25:732-741.

8 Hoefnagel JJ, Dijkman R, Basso K, et al. Distinct types of primary cutaneous B-cell lymphoma identified by gene expression profiling. Blood 2005;105:3671-3678.

9 Willemze R, Jaffe E, Burg G, et al. WHO-EORTC classification for cutaneous lymphomas. Blood 2005; 105:3768-3785.

10 Barrans SL, Fenton JA, Banham A, et al. Strong expression of FOXP1 identifies a distinct subset of diffuse large B-cell lymphoma (DLBCL) patients with poor outcome. Blood 2004;104:2933-2935.

11 Hans CP, Weisenburger DD, Greiner TC, et al. Confirmation of the molecular classification of diffuse large B-cell lymphoma by immunohistochemistry using a tissue microarray. Blood 2004;103:275-282.

12 Busslinger M. Transcriptional control of early B-cell development. Annu Rev Immunol 2004;22:55-79.

13 Johnson K, Shapiro-Shelef M, Tunyaplin C, et al. Regulatory events in early and late B-cell differentiation. Mol Immunol 2005;42:749-761.

14 Bartholdy B, Matthias P. Transcriptional control of Bcell development and function. Gene 2004;327:1-23.

15 Krenacs L, Himmelmann AW, Quintanilla-Martinez L, et al. Transcription factor B-cell specific activator protein (BSAP) is differentially expressed in B-cells and in subsets of B-cell lymphomas. Blood 1998;92: 1308-1316.

16 DeKoter RP, Singh H. Regulation of B-lymphocyte and macrophage development by graded expression of PU.1. Science 2000;288:1439-1441.

17 Loddenkemper C, Anagnosopoulos I, Hummel M, et al. Differential $\mathrm{E} \mu$ enhancer activity and expression of BOB.1/OBF.1, Oct2, PU.1, and immunoglobulin in reactive B-cell populations, B-cell non-Hodgkin lymphomas, and Hodgkin lymphomas. J Pathol 2004;202: 60-69.

18 Catoretti G, Chang CC, Cechova K, et al. BCL-6 protein is expressed in germinal-center B-cells. Blood 1995;86: 45-53.

19 Mittrucker HW, Matsuyama T, Grossman A, et al. Requirement for the transcription factor LSIRF/IRF4 for mature $\mathrm{B}$ and $\mathrm{T}$ lymphocyte function. Science 1997;275:540-543.

20 Falini B, Fizzoti M, Pucciarini A, et al. A monoclonal antibody (MUM1/IRF4p) detects expression of the MUM1/IRF4/IRF4 protein in a subset of germinal center B-cells, plasma cells, and activated T-cells. Blood 2000;95:2084-2092.

21 Carbone A, Gloghini A, Larocca LM, et al. Expression profile of MUM1/IRF4, BCL-6, and CD138/syndecan-1 defines novel hisogenetic subsets of human immunodeficiency virus-related lymphomas. Blood 2001;97: 744-751.

22 Angelin-Duclos C, Catoretti G, Lin K, et al. Commitment to B lymphocytes to a plasma cell fate is associated with BLIMP-1 expression in vivo. J Immunol 2000;165:5462-5471.

23 Banham AH, Beasley N, Campo E, et al. The FOXP1 winged helix transcription factor is a novel candidate tumor suppressor gene on chromosome 3p. Cancer Res 2001;61:8820-8829.

24 Kodama K, Massone C, Chott A, et al. Primary cutaneous large B-cell lymphoma. Clinicopathologic features, classification, and prognostic factors in a large serie of patients. Blood 2005;106:2491-2497.

25 Hallermann C, Kaune KM, Neumann C, et al. Molecular cytogenetic analysis of chromosomal breakpoints in the IGH, MYC, BCL6 and MALT1 gene loci in primary cutaneus B-cell lymphomas. J Invest Dermatol 2004;123:213-219.

26 Geelen FAMJ, Vermeer MH, Meijer CJLM, et al. Bcl-2 expression in primary cutaneous large B-cell lymphoma is site-related. J Clin Oncol 1998;16:20802085.

27 Cerroni L, Arzberger E, Pütz B, et al. Primary cutaneous follicular center cell lymphoma with follicular growth pattern. Blood 2000;95:3922-3928.

28 Wlodarska I, Veyt E, De Paepe P, et al. FOXP1, a gene highly expressed in a subset of diffuse large B-cell lymphoma is recurrently targeted by genomic aberrations. Leukemia 2005;19:1299-1305.

29 Streubel B, Vinatzer U, Lamprecht A, et al. $\mathrm{T}(3 ; 14)(\mathrm{p} 14.1 ; \mathrm{q} 32)$ involving IGH and FOXP1 is a novel recurrent chromosomal aberration in MALT lymphoma. Leukemia 2005;19:652-658. 